\title{
Value-added organonitrogen chemicals evolution from the pyrolysis of chitin and chitosan
}

Chao Liu ${ }^{\mathrm{a}, \mathrm{b}}$, Huiyan Zhang ${ }^{\mathrm{a}}$, Rui Xiao ${ }^{\mathrm{a}, *}$, Shubin $\mathrm{Wu}^{\mathrm{b}, * *}$

${ }^{a}$ Key Laboratory of Energy Thermal Conversion and Control of Ministry of Education, Southeast

University, Nanjing 210096, PR China

${ }^{\text {b}}$ State Key Laboratory of Pulp and Paper Engineering, South China University of Technology,

Guangzhou 510640, PR China

*Corresponding author. Tel.: +86-25-83795726. Fax:+86-25-57714489. E-mail: ruixiao@ @eu.edu.cn.

**Corresponding author. Tel./Fax: +86-20-22236808. E-mail address: shubinwu@ scut.edu.cn.

\section{GRAPHICAL ABSTRACT}
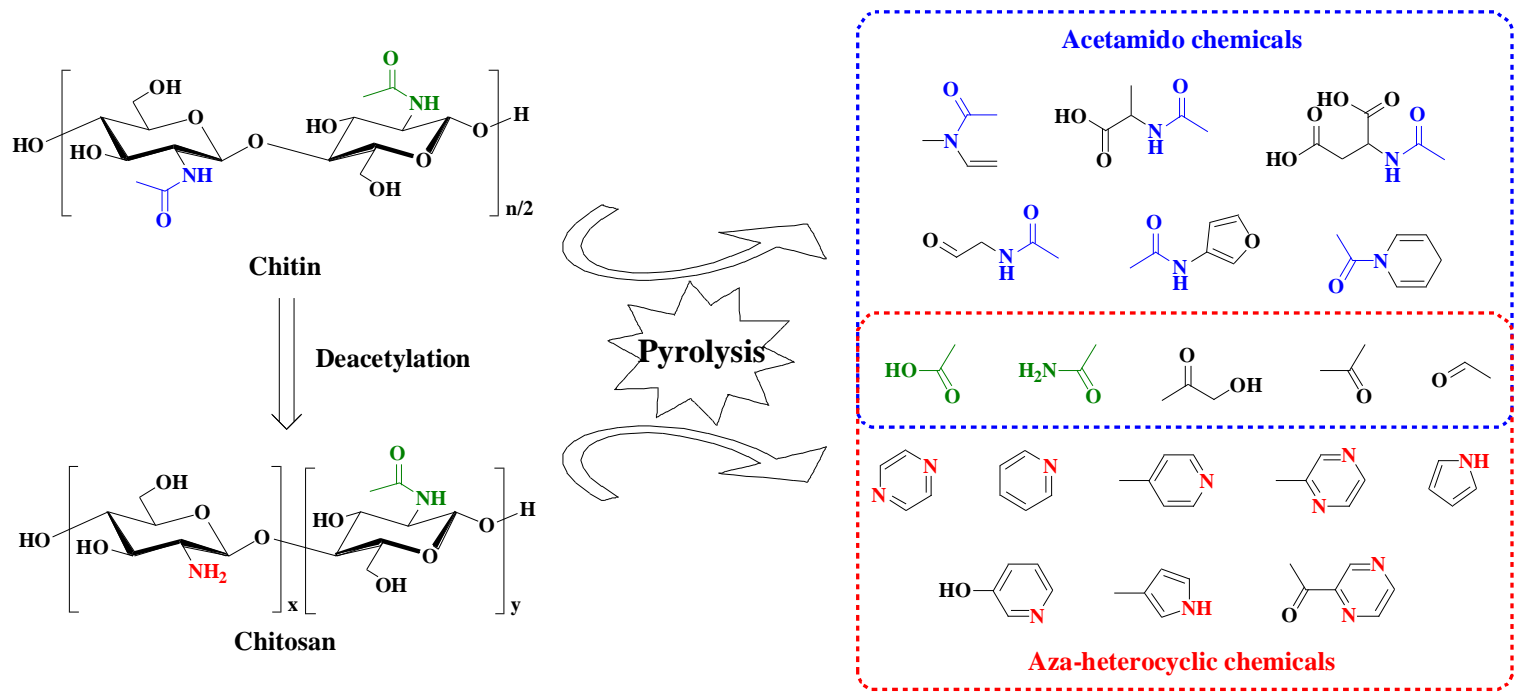

1

(C) 2016. This manuscript version is made available under the Elsevier user license http://www.elsevier.com/open-access/userlicense/1.0/ 


\section{ABSTRACT}

Thermogravimetric characteristics of chitin and chitosan and their potentials to produce value-added organonitrogen chemicals were separately evaluated via TG/DSC-FTIR and Py-GC/MS. Results shown that chitin had the better thermal stability and higher activation energy than chitosan because of the abundant acetamido group. Furthermore, the dominated volatilization in active pyrolysis of chitin contributed to its endothermic property, whereas the charring in chitosan led to the exothermal. During fast pyrolysis, the acetamido group in chitin and chitosan was converted into acetic acid or acetamide. Typical products from chitosan pyrolysis were aza-heterocyclic chemicals, i.e. pyridines, pyrazines, and pyrroles, with the total selectivity of $50.50 \%$ at $600{ }^{\circ} \mathrm{C}$. Herein, selectivity of pyrazine compounds was up to $22.99 \%$. These aza-heterocyclic chemicals came from the nucleophilic addition reaction of primary amine and carbonyl. However, main reaction during chitin pyrolysis was ring-opening degradation, which led to the formation of acetamido chemicals, especially acetamido acetaldehyde with the highest selectivity of $27.27 \%$ at $450{ }^{\circ} \mathrm{C}$. In summary, chitosan had the potential to produce aza-heterocyclic chemicals, and chitin to acetamido chemicals.

Keywords: Chitin; Chitosan; Pyrolysis; Organonitrogen chemicals; TG/DSC-FTIR; Py-GC/MS 


\section{Introduction}

Chitin is the second most abundant biopolymer on earth after cellulose, and the annual production is up to $10^{11}$ tonnes. It widely exists in the exoskeleton of crustacean and insects, the cell walls of fungi, etc., and is polymerized by $\mathrm{N}$-acetyl-D-glucosamine with the $\beta$-(1 $\rightarrow 4)$-glucosidic bonds (Zeng, $\mathrm{Hu}, \mathrm{Gu}, \mathrm{Fu}, \&$ Qin, 2015; Baran, Menteş, \& Arslan, 2015; Baran \& Menteş, 2015). On account of the distinctive structure and properties, chitin and its deacetylated product, viz. chitosan, are widely applied in the fields of agriculture, environmental protection, functional food, biomedical and biotechnology engineering, and textile industry, especially prepared as hydrogels and drug delivery materials (Kumar, 2010; Kumar, Muzzarelli, Muzzarelli, Sashiwa, \& Domd, 2004; Baran, Inanan, \& Menteş, 2016; Baran, Açıksöz, \& Menteş, 2016). Recently, in order to reduce the dependence on fossil resources, various biomass (including cellulose, hemicellulose, and lignin) were converted into value-added bio-chemicals, such as furan compounds (Mettler et al., 2012; Wang, Ren, Li, Deng, \& Sun, 2015) and phenol compounds (Hu, Shen, Xiao, Wu, \& Zhang, 2013; Singh \& Ekhe, 2014). However, less attention has been paid on the conversion and utilization of chitin and chitosan.

Previous research reported that chitin can be directly transformed to

3-acetamido-5-acetylfuran in solution with catalysts by the reconstruction of the pyranose ring (Chen, Chew, Kerton, \& Yan, 2014; Chen, Gao, Wang, Chen, \& Yan, 2015).

However, these obtained furan derivatives did not perform much more difference with that derived from cellulose and hemicellulose. Apart from solvolysis, pyrolysis is another 
promising thermochemical technology (Bridgwater, Meier, \& Radlein, 1999), which could convert biomass into value-added bio-fuel and bio-chemical rapidly. Initially, pyrolysis was used to detect the chitin in fossil arthropods (Bierstedt, Stankiewicz, Briggs, \& Evershed, 1998) and molluscan shells (Furuhashi et al., 2009), and determine the amine content or the degree of acetylation of chitosan (Lal \& Hayes, 1984; Sato et al., 1998). Afterwards, pyrolysis was used to investigate the thermogravimetric characteristics and kinetics of chitin and chitosan according to various dynamic models (Stolarek \& Ledakowicz, 2005; Tang, Wang, \& Chen, 2005; Zeng, Qin, Wang, \& Li, 2011). Recently, research on chitin and chitosan pyrolysis turns to focus on their thermal conversion. Zeng et al. (2011; 2015) and Qiao et al. (2015) detected the volatiles from the thermogravimetric processes of chitin and chitosan using TG-FTIR and TG-MS respectively. Furthermore, bio-oil from the fast pyrolysis of chitin and chitosan was off-line identified (Zeng, Qin, Wang, \& Li, 2011; Zeng, Hu, Gu, Fu, \& Qin, 2015). Herein, major product from chitin pyrolysis was acetamide, whereas those from chitosan pyrolysis were pyrazines. These organonitrogen chemicals are important intermediates in the chemical and pharmaceutical industries, and have substantially greater market value than chitin or chitosan.

However, previous reports on pyrolysis of chitin or chitosan only exhibited their individual properties, but could not present their distinction, as well as the relevance between their thermal conversions. Hence, systematic comparative studies of chitin and chitosan on their thermal stability, kinetics, products distribution, as well as pyrolysis 
mechanism, were carried out using the thermogravimetric analyzer and analytical pyrolyzer to evaluate the potentials of these two natural amino polysaccharides to produce value-added organonitrogen chemicals.

\section{Materials and methods}

\subsection{Materials}

Materials used in this study were chitin and chitosan, whose chemical structural formulas were shown in Fig. 1. Chitin was separated from shrimp shell, and purchased from Aladdin Industrial Corporation (Shanghai, China). Chitosan, prepared from crab shell, was supplied by Jinan Haidebei Marine Bioengineering Co., Ltd. (Jinan, China). Its degree of deacetylation determined by acid-base titration (Kasaai, 2009) was $85 \%$, and weight-average molecular weight measured by gel permeation chromatography method (Li et al., 2012) was $2.5 \times 10^{5} \mathrm{~g} / \mathrm{mol}$. The two materials were only dried again in a vacuum oven at room temperature for $24 \mathrm{~h}$ before using.
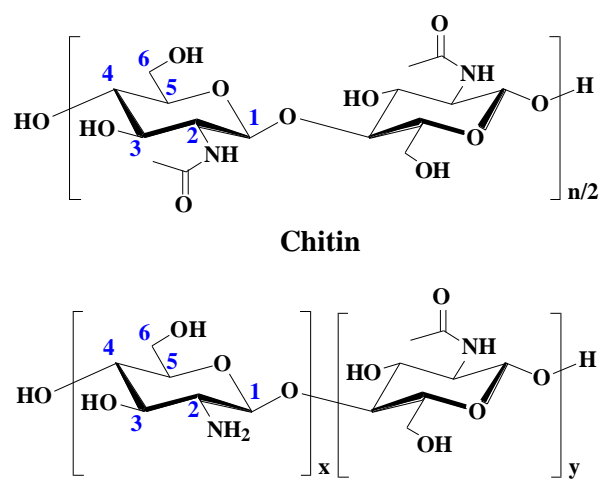

Chitosan

Fig. 1 Chemical structural formulas of chitin and chitosan: $n, x$, and $y$ : degree of polymerization; $\mathrm{x}$ : y equals 17: 3 . 


\subsection{TG/DSC-FTIR}

TG/DSC-FTIR experiments were carried out on a STA 449 F3 Jupiter thermogravimetric analyzer (NETZSCH, Germany) coupled with a TENSOR 27 Fourier transformation infrared spectrometer (Bruker, Germany). High-purity nitrogen (99.999\%) was used as the carrier gas with a flow rate of $20 \mathrm{~mL} / \mathrm{min}$. In each case, about $5 \mathrm{mg}$ of sample was loaded in the ceramic crucible, and heated from $40{ }^{\circ} \mathrm{C}$ to $850{ }^{\circ} \mathrm{C}$ with a heating rate of $20{ }^{\circ} \mathrm{C} / \mathrm{min}$. Volatiles released from the pyrolysis were quickly swept into a Fourier transform infrared spectrometer gas cell by nitrogen. Moreover, before each experiment, the FTIR gas cell and the pipe were already preheated to $150{ }^{\circ} \mathrm{C}$. The spectrum scope was located in the range from $4000 \mathrm{~cm}^{-1}$ to $667 \mathrm{~cm}^{-1}$ and the resolution factor was set at $4 \mathrm{~cm}^{-1}$.

\subsection{Char characterization}

Char residues from the thermogravimetric processes of chitin and chitosan were characterized by the Fourier transform infrared (FTIR) spectrometry and the solid-state cross-polarization magic angle spinning (CP/MAS) ${ }^{13} \mathrm{C}$-nuclear magnetic resonance (NMR). FTIR was programmed on a VECTOR 22 FTIR spectrometer (Bruker, Germany). Samples were pressed into a $\mathrm{KBr}$ disc with a mass ratio of 1:50. The spectra were scanned in the range from $4000 \mathrm{~cm}^{-1}$ to $400 \mathrm{~cm}^{-1}$ with a resolution of $4 \mathrm{~cm}^{-1}$. Solid-state CP/MAS ${ }^{13} \mathrm{C}-\mathrm{NMR}$ was carried out on an AVANCE III HD 400 superconducting Fourier transform NMR spectrometer (Bruker, Germany) at $100 \mathrm{MHz}$ acquired in 
cross-polarization conditions with a spinning rate of $5 \mathrm{kHz}$, and the spectra were composed of 2000 scans.

\subsection{Fast pyrolysis}

Fast pyrolysis of chitin and chitosan were investigated on a CDS 5200 analytical pyrolyzer (CDS Analytical, USA) coupled with a 7890A gas chromatography and a 5975C mass spectrometry (Agilent Technologies, USA) (Py-GC/MS). Samples ( 0.5 mg) were loaded in the pyrolysis tube and pyrolyzed at 350,450 , and $600{ }^{\circ} \mathrm{C}$ for $20 \mathrm{~s}$ with a heating rate of $10000^{\circ} \mathrm{C} / \mathrm{s}$. The split ratio was $50: 1$, and the flow rate of helium (carrier gas) was $1.00 \mathrm{~mL} / \mathrm{min}$. The injector, detector, and interface temperatures of GC/MS were all set at $250{ }^{\circ} \mathrm{C}$. An HP-INNOWax capillary column $(30 \mathrm{~m} \times 0.25 \mathrm{~mm} \times 0.25 \mu \mathrm{m})$ was selected as the separation column. The column temperature was programmed from $50{ }^{\circ} \mathrm{C}$ to $250{ }^{\circ} \mathrm{C}(10 \mathrm{~min})$ with a heating rate of $5{ }^{\circ} \mathrm{C} / \mathrm{min}$. The mass spectrometer was set at an ionizing voltage of $70 \mathrm{eV}$, and the mass range from $\mathrm{m} / \mathrm{z} 5$ to 400 was scanned with a speed of $1.0 \mathrm{~s} /$ decade. Data processing was performed using Perkin Elmer NIST Spectral Version 5 software (USA).

\section{Results and discussion}

\subsection{TG, DSC, and kinetics}

The thermogravimetry (TG) and differential thermogravimetry (DTG) curves of chitin and chitosan with the heating rate of $20^{\circ} \mathrm{C} / \mathrm{min}$ were presented in Fig. 2. Three 
degradation stages can be recognized in the thermogravimetric processes of both chitin and chitosan (Liang et al., 2015; Yang, Yan, Chen, Lee, \& Zheng, 2007). The first stage was the dehydration process, which basically occurred before $150{ }^{\circ} \mathrm{C}$. The second stage was known as the active pyrolysis process. In this stage, feedstock degradation and volatile releasing occurred heavily. The third stage was the positive pyrolysis process, which benefited from the redecomposition and carbonization of the char residue. As summarized in Table 1, the degradation parameters of the two samples were different. $T_{\text {oneset }}$ of chitosan was $203{ }^{\circ} \mathrm{C}$, which was $25{ }^{\circ} \mathrm{C}$ lower than that of chitin. $T_{\text {peak }}$ of chitosan was $312{ }^{\circ} \mathrm{C}$, whereas $T_{\text {peak }}$ of chitin was $388^{\circ} \mathrm{C}$. Furthermore, $R_{\text {peak }}$ of chitosan $\left(-1.252 \% \cdot{ }^{\circ} \mathrm{C}^{-1}\right)$ was lower than that of chitin $\left(-0.973 \% \cdot{ }^{\circ} \mathrm{C}^{-1}\right)$ as well. During the whole process, the mass loss of chitin was $77.06 \mathrm{wt} \%$, and that of chitosan was $65.97 \mathrm{wt} . \%$. All those differences between chitin and chitosan were in consisted with the literatures (Qiao et al., 2015; Tang, Wang, \& Chen, 2005), which were caused by the different chemical structures, mainly the different contents of the amino and acetamido group.

Fig. 2 also displayed the differential scanning calorimetry (DSC) curves of chitin and chitosan with the heating rate of $20^{\circ} \mathrm{C} / \mathrm{min}$. As can be seen from the DSC carves, when temperature was lower than $200{ }^{\circ} \mathrm{C}$, there was an obviously endothermic peak. This attributed to the energy required to evaporate the absorbed water (Yang, Yan, Chen, Lee, $\&$ Zheng, 2007). With temperature rising up, the DSC profile of chitin showed another endothermic peak at $390{ }^{\circ} \mathrm{C}$, and correspondingly, $95.3 \mathrm{~J} / \mathrm{g}$ of heat was absorbed. However, different with chitin, during the positive pyrolysis phase of chitosan, $391.6 \mathrm{~J} / \mathrm{g}$ 
of heat was given off. Ball, Mcintosh, \& Brindley (2004) pointed out that the charring process was highly exothermal whereas volatilization was endothermal. Furthermore, volatilization and charring reactions did exist simultaneously during the positive pyrolysis. Therefore, it could be concluded that volatilization was the dominant reaction in the positive pyrolysis of chitin, whereas the dominant reaction in chitosan was charring. The easy charring characteristic of chitosan also led to its high $Y_{\text {char, }}$ as reflected in Fig. 2 and Table 1 . After $500{ }^{\circ} \mathrm{C}$, the two DSC carves kept moving to minus without any obvious peaks. The endothermal properties of both chitin and chitosan in this high-temperature region indicated the further decomposition of formed char residues, which were consistent with the slow weightlessness during the TG processes.

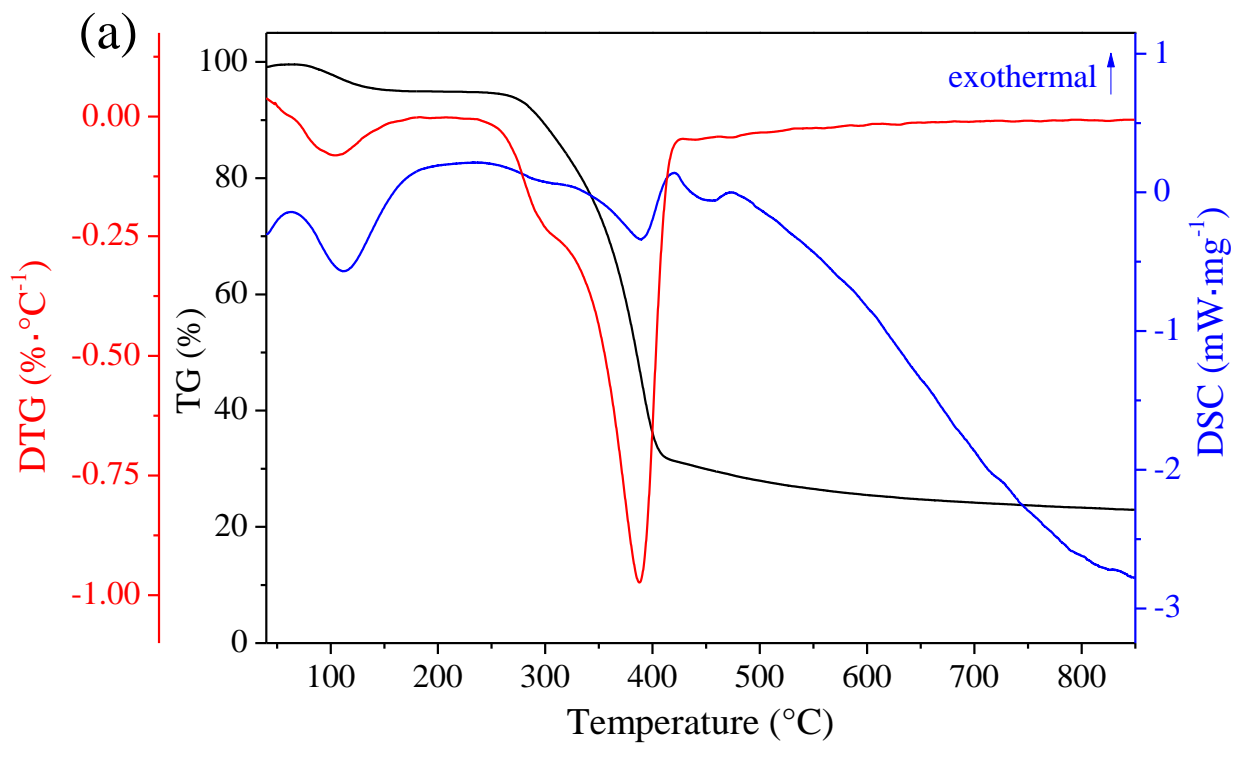




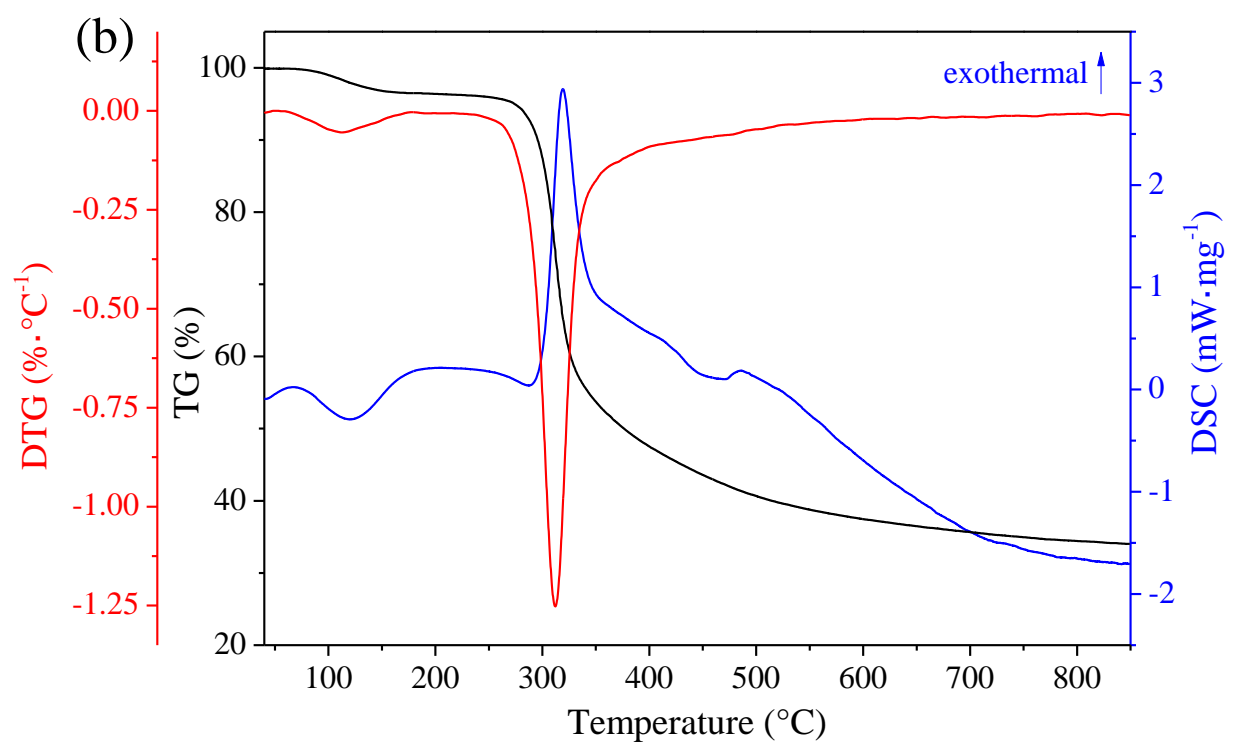

Fig. 2 TG, DTG, and DSC curves of chitin (a) and chitosan (b) with the heating rate of $20{ }^{\circ} \mathrm{C} / \mathrm{min}$

Table 1 Summary of degradation characteristics of chitin and chitosan

\begin{tabular}{|c|c|c|c|c|c|c|c|}
\hline Sample & $T_{\text {oneset }}\left({ }^{\circ} \mathrm{C}\right)$ & $T_{\text {peak }}\left({ }^{\circ} \mathrm{C}\right)$ & $T_{\text {offset }}\left({ }^{\circ} \mathrm{C}\right)$ & $R_{\text {peak }}\left(\% \cdot{ }^{\circ} \mathrm{C}^{-1}\right)$ & $Y_{\text {char }}(\mathrm{wt} . \%)$ & $Q\left(\mathrm{~J} \cdot \mathrm{g}^{-1}\right)$ & $T_{Q}\left({ }^{\circ} \mathrm{C}\right)$ \\
\hline Chitin & 228 & 388 & 434 & -0.973 & 22.94 & -95.3 & 390 \\
\hline Chitosan & 203 & 312 & 424 & -1.252 & 34.03 & 391.6 & 319 \\
\hline
\end{tabular}

$T_{\text {onset }}$ is defined as the temperature for the beginning of active pyrolysis. $T_{\text {peak }}$ is the temperature corresponding to the maximum degradation rate. $T_{\text {offset }}$ is extrapolated as the termination temperature of active pyrolysis and the beginning temperature of positive pyrolysis. $R_{\text {peak }}$ is the maximum degradation rate. The char yield is identified by $Y_{\text {char }}$, which is the percent of the solid mass fraction detected from the end of the non-isothermal pyrolysis $\left(850^{\circ} \mathrm{C}\right) . Q$ is the heat gave off during the active pyrolysis 
phase. $T_{Q}$ is recognized as the temperature of the maximum exothermic peak.

According to the non-isothermal pyrolysis model, the simplified Coats-Redfern equation (Dong \& Xiong, 2014) was used to govern the kinetic process in the following form:

when $\mathrm{n}=1, \ln \left[\frac{-\ln (1-\alpha)}{T^{2}}\right]=\ln \left[\frac{A R}{\beta E}\right]-\frac{E}{R T}$

when $\mathrm{n} \neq 1, \quad \ln \left[\frac{1-(1-\alpha)^{1-n}}{T^{2}(1-n)}\right]=\ln \left[\frac{A R}{\beta E}\right]-\frac{E}{R T}$

where $\alpha$ is the mass loss $(\%), n$ is the reaction order, $T$ is the absolute temperature $(\mathrm{K}), \beta$ is the heating rate $(\mathrm{K} / \mathrm{s}), A$ is the pre-exponential factor $\left(\mathrm{s}^{-1}\right), E$ is the apparent activation $\operatorname{energy}\left(\mathrm{J} \cdot \mathrm{mol}^{-1}\right)$, and $R$ is the gas constant $\left(8.314 \mathrm{~J} \cdot \mathrm{mol}^{-1} \cdot \mathrm{K}^{-1}\right)$.

With the iterative method, it was found that the linear correlation coefficient of $\ln \left[\left(1-(1-\alpha)^{1-n}\right) /\left(T^{2}(1-n)\right)\right]$ against $1 / T$ when $\mathrm{n} \neq 1$ was lower than that of $\ln \left[-\ln (1-\alpha) / T^{2}\right]$ versus $1 / T$ when $n=1$. Thus, the first-order kinetic model was determined with Eq. (1). Correspondingly, the apparent activation energy $(E)$, the pre-exponential factor $(A)$, and the linear correlation coefficient $\left(R^{2}\right)$ were obtained and listed in Table 2 . The calculated $E$ value during chitin pyrolysis was $118.12 \mathrm{~kJ} \cdot \mathrm{mol}^{-1}$, which was slightly higher than that of chitosan pyrolysis $\left(112.78 \mathrm{~kJ} \cdot \mathrm{mol}^{-1}\right)$. Similar result can be found in the work of Tang, Wang, \& Chen (2005) (entry 3 and 4 in Table 2) that the $E$ value of chitin pyrolysis was also higher than that of chitosan pyrolysis. This was in consistent with their thermal 
stabilities, as discussed above. Furthermore, the gap between these $E$ values of the same feedstock (entry 1,3, and 5, or entry 2, 4, and 6) might be caused by the different experimental parameters (mainly the heating rate $\beta$ ), as well as the different kinetic models.

Table 2 Summary of kinetic parameters of chitin and chitosan pyrolysis

\begin{tabular}{|c|c|c|c|c|c|c|}
\hline Entry & Sample & Method & $\begin{array}{l}\text { Temp. } \\
\left({ }^{\circ} \mathrm{C}\right)\end{array}$ & $\begin{array}{c}E \\
\left(\mathrm{~kJ} \cdot \mathrm{mol}^{-1}\right)\end{array}$ & $A\left(\mathrm{~s}^{-1}\right)$ & $R^{2}$ \\
\hline 1 & Chitin (present work) & Coats-Redfern & $228-434$ & 118.12 & $4.10 \times 10^{7}$ & 0.966 \\
\hline 2 & Chitosan (present work) & Coats-Redfern & $203-424$ & 112.78 & $3.46 \times 10^{7}$ & 0.953 \\
\hline 3 & $\begin{array}{c}\text { Chitin (Tang, Wang, \& Chen, } \\
\text { 2005) }\end{array}$ & Friedman & $287-427^{\mathrm{a}}$ & 221 & $\begin{array}{c}1.52-1.85 \times \\
10^{17}\end{array}$ & - \\
\hline 4 & $\begin{array}{c}\text { Chitosan (Tang, Wang, \& } \\
\text { Chen, 2005) }\end{array}$ & Miura-Maki & - & 189 & $1.01 \times 10^{15}$ & - \\
\hline 5 & $\begin{array}{l}\text { Chitin (Stolarek \& } \\
\text { Ledakowicz, 2005) }\end{array}$ & Kissinger & $200-400$ & $155.3^{\mathrm{a}}$ & $2.51 \times 10^{10 a}$ & - \\
\hline 6 & $\begin{array}{c}\text { Chitosan (Zeng, Qin, Wang, } \\
\text { \& Li, 2011) }\end{array}$ & $\begin{array}{c}\text { Ozawa-Flynn- } \\
\text { Wall }\end{array}$ & $252-377^{a}$ & 137 & - & - \\
\hline
\end{tabular}

-: Unavailable.

${ }^{a}$ Recalculated. 
3.2 Volatiles and char evolution from TG

As Fig. 3 depicted, during the thermogravimetric processes, common volatiles from both chitin and chitosan were $\mathrm{H}_{2} \mathrm{O}, \mathrm{CO}_{2}$, acetyl compounds, and hydroxyl compounds (Zeng, Qin, Wang, \& Li, 2011; Zeng, Hu, Gu, Fu, \& Qin, 2015). Herein, the release of $\mathrm{H}_{2} \mathrm{O}$ involved three possible pathways: the dehydration between two hydroxyl groups to build the oxygen-bridged bond, the multiple dehydration of hydroxyl groups, as well as the further degradation and repolymerization of pyrolysis products. The release of $\mathrm{CO}_{2}$ mainly benefitted from the further decomposition of ring-opened pyrolysis products (Wang, Ru, Lin, \& Luo, 2013). Moreover, there was no doubt that those acetyl compounds came from the cleavage of the amide bonds at the side-chain structure; and those hydroxyl compounds were from the ring-opening degradation. Notably, signals of aromatic heterocyclics were observed from the pyrolysis of chitosan (Zeng, Qin, Wang, \& Li, 2011), which was the result of volatile aromatization. In short, during the thermogravimetric processes, chitin and chitosan underwent hydroxyl removal, side-chain breakage, ring-opening degradation, and structural reorganization. 


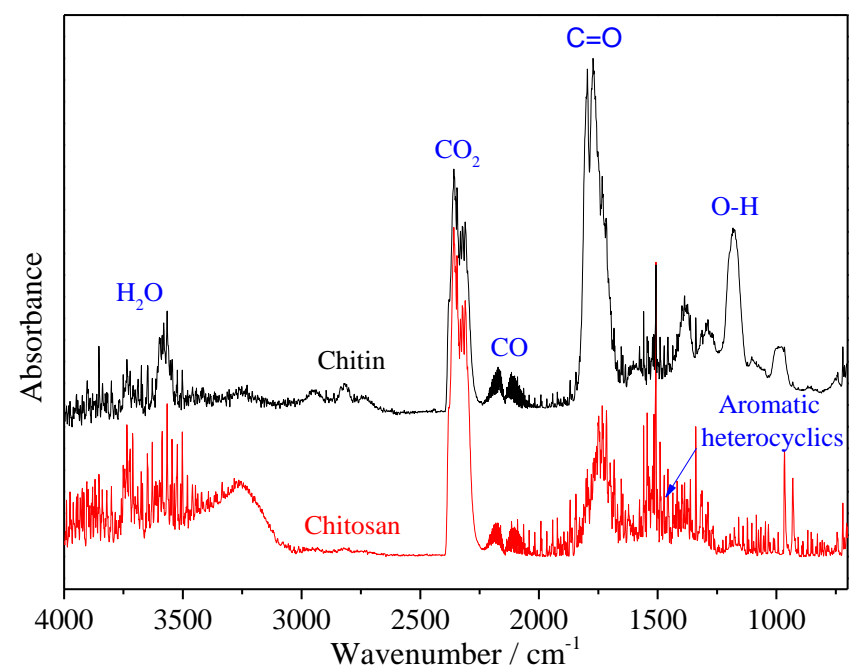

Fig. 3 FTIR spectra of volatiles evolution from chitin and chitosan at $T_{\text {peak }}$

With the release of volatiles, the char residue was remained. To the end of the thermogravimetric process, $Y_{\text {char }}$ from chitin and chitosan were separately 22.94 wt. $\%$ and 34.03 wt.\%. As can be seen from the FTIR spectra in Fig. 4(a), apart from the remaining signals of $\mathrm{O}-\mathrm{H}$ and $\mathrm{C}-\mathrm{H}$, there was a broad absorption with maximum around $1590 \mathrm{~cm}^{-1}$ and mutually overlapping bands in the region of $1100-1500 \mathrm{~cm}^{-1}$. This band was probably due to a $\mathrm{C}=\mathrm{C}$ stretching mode (Kaczmarek \& Zawadzki, 2010). In order to further determine the structure of the char residues from chitin and chitosan, solid-state CP/MAS ${ }^{13}$ C-NMR was introduced. As spectra shown in Fig. 4(b), apart from the signals of aromatic nuclei, there were no other significant signals. This indicated the aromatic structure in the char residues, and agreed with the results of FTIR, as well as the char aromatization phenomena verified by model compounds (Qiao et al., 2015). Furthermore, similar results were also discovered in the pyrolysis of cellulose (Dumanlı \& Windle, 
2012; Pastorova, Botto, Arisz, \& Boon, 1994). Formation mechanism of char residues with aromatic structure during cellulose pyrolysis had been proposed (Dumanlı \& Windle, 2012), and the revolution of char residues from chitin and chitosan were considered to undergo similar processes. However, the difference was that the char residues from chitin and chitosan were nitrogen-doped (Qiao et al., 2015; Zhao et al., 2010).
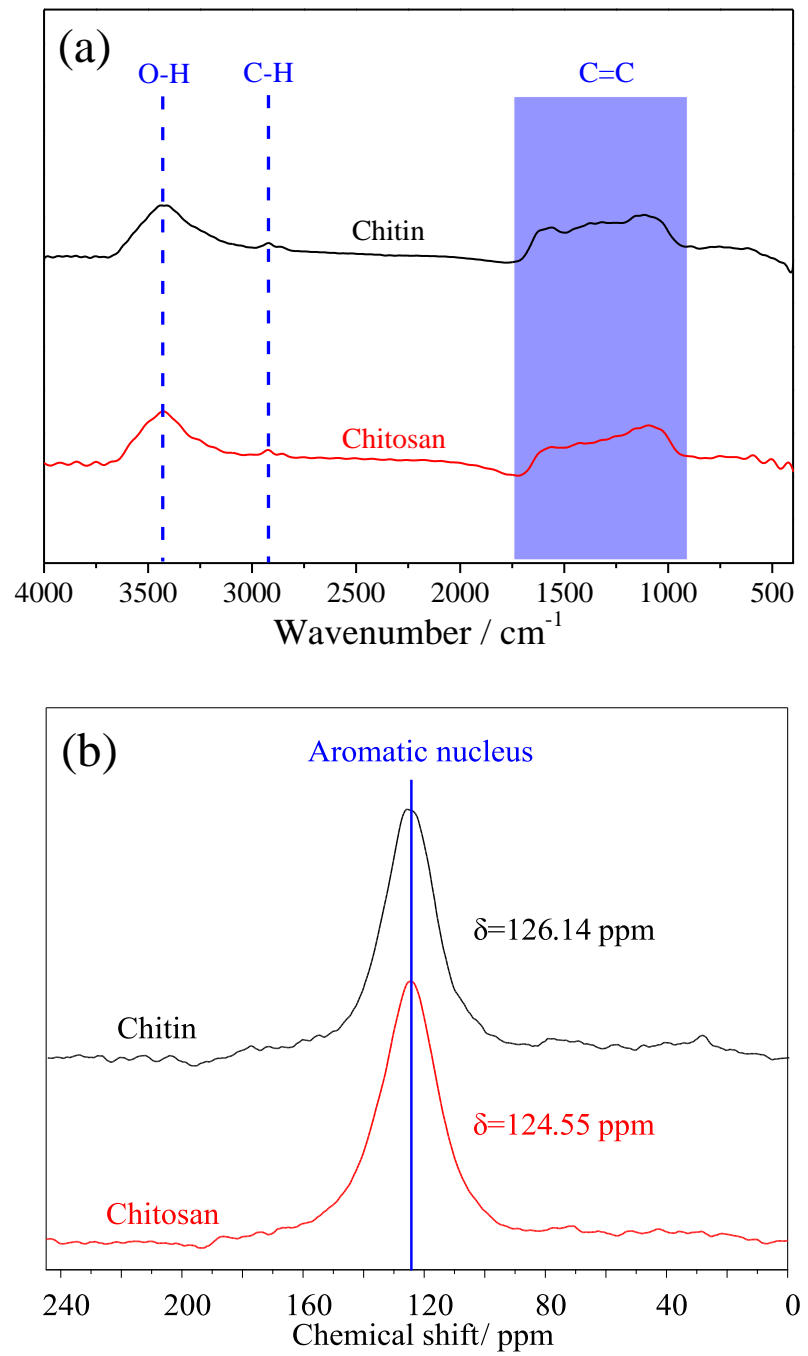

Fig. 4 FTIR (a) and solid-state CP/MAS ${ }^{13} \mathrm{C}-\mathrm{NMR}$ (b) spectra of the char residues from the thermogravimetric processes of chitin and chitosan 
3.3. Aza-heterocyclic chemicals from the fast pyrolysis of chitosan

Pyrolysis products from chitosan under 350,450 , and $600{ }^{\circ} \mathrm{C}$ were illustrated in Fig. S2(a), and summarized in Table S1. As can be seen intuitively, species and selectivity of these products changed greatly when the temperature increased. Under all the three pyrolysis temperatures, pyrazine, acetic acid, and acetamide were always the major products. Acetic acid and acetamide were formed from the evolution of the acetamido groups. The highest selectivity of acetamide reached $36.32 \%$ at $350{ }^{\circ} \mathrm{C}$, and that of acetic acid was $24.13 \%$ at $450{ }^{\circ} \mathrm{C}$. Considering from the content of the acetamido group in chitosan ( $85 \%$ of the deacetylation degree), the high selectivity of acetic acid and acetamide suggested the easy removal of the acetamido groups during the pyrolysis of chitosan. As another major product, pyrazine was released from the heterocyclic aromatization process with the highest selectivity of $15.05 \%$ at $350{ }^{\circ} \mathrm{C}$. Its detailed formation routes, as well as the formation routes of other aza-heterocyclic chemicals (pyridine, pyrrole, and their derivatives), would be discussed in the following part. Furthermore, other small-molecule products were mainly produced through the ring-opening degradation, similar with the pyrolysis decomposition of cellulose (Mettler et al., 2012; Shen \& Gu, 2009).

Among these aza-heterocyclic chemicals released from the fast pyrolysis of chitosan, pyrazine compounds were the dominated products, whose total selectivity was up to $22.99 \%$ at $600{ }^{\circ} \mathrm{C}$. Their formation was restricted by the nucleophilic addition reaction of two $\alpha$-aminocarbonyls, just as Chen $\&$ Ho (1998) proofed with glucosamine (the major 
polymerization units of chitosan) that the $\alpha$-aminocarbonyls were considered to be the precursors of pyrazine compounds. During the pyrolysis of chitosan, the cleavage of the glycosidic bond and the ring-opening from the $\mathrm{C}_{1}-\mathrm{O}$ bond breaking (as marked in Fig. 5) contributed to the formation of the aldehyde group at $\mathrm{C}_{1}$, which combined with the amino group at $\mathrm{C}_{2}$ to form the $\alpha$-aminocarbonyl structure (intermediate 1 , abbreviated as IM 1). Subsequently, the bimolecular nucleophilic addition reaction occurred and led to the formation of pyrazine compounds, as path 1 described in Fig. 5. Meanwhile, with the free radical (at $\mathrm{C}_{4}$ in IM 1) transferring, the hydroxyl group at $\mathrm{C}_{3}$ changed into the carbonyl group (IM 2). The $\alpha$-aminocarbonyl structure could be also recognized in IM 2 (highlighted in blue in Fig. 5), which would induce the formation of pyrazine compounds as well (path 2 and 3 in Fig. 5). Furthermore, inspired by the ring-opening reactions during cellulose pyrolysis (Shen \& $\mathrm{Gu}, 2009$ ), the $\mathrm{C}_{2}-\mathrm{C}_{3}$ bond in chitosan could be further fractured. As a result, chitosan was fragmented into aminoacetaldehyde and IM 3 (path 4 in Fig. 5). Because of the less steric hindrance and electronic effect, i.e., without any substituents, aminoacetaldehyde was easier to be involved in the nucleophilic addition reaction to produce pyrazine compounds. Meanwhile, this explanation was also considered as the reason for the absence of aminoacetaldehyde in Table S1. 


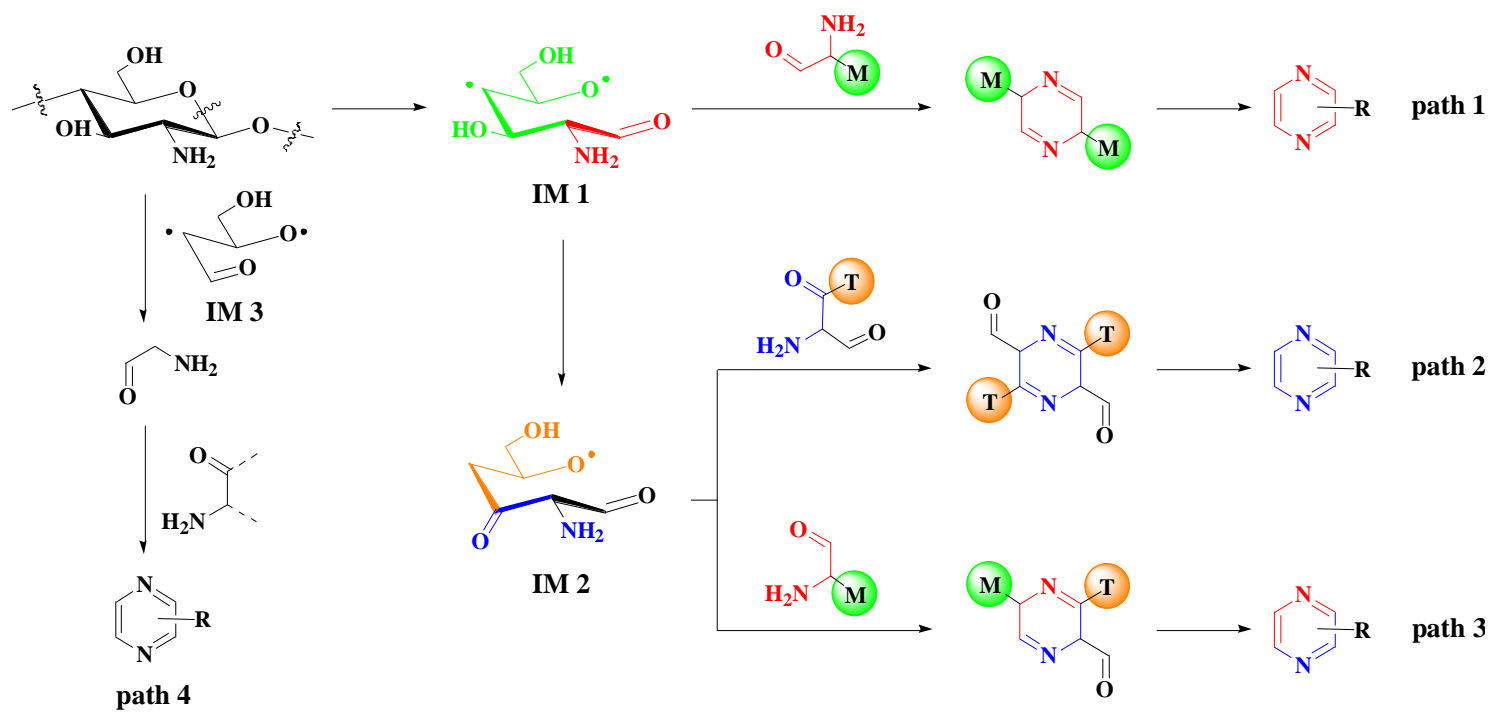

Fig. 5 Proposed formation processes of pyrazine compounds from the fast pyrolysis of chitosan

Different with the results of Chen \& Ho (1998) and Zeng, Qin, Wang, \& Li (2011), no furyl pyrazines were detected in this work, whereas, they were identified as the major products in literatures. This phenomenon was probably caused by the different experimental systems, i.e., the different heat and mass transfer processes. In literatures (Chen \& Ho, 1998; Zeng, Qin, Wang, \& Li, 2011), equipments were both the home-made pyrolysis reactors, and the mild pyrolysis temperatures were kept for a long time. Under these parameters, the cyclization reaction would occur on the branched chains (mainly the M group in Fig. 5), resulting in the formation of furyl pyrazines. However, pyrolysis in this work was operated on Py-GC/MS. The instantaneous high energy cracked the branched chains, both the $\mathrm{M}$ and $\mathrm{T}$ group in Fig. 5. Therefore, no furyl pyrazines were produced in our experiments, replaced by pyrazine, methyl pyrazine, ethyl pyrazine, and 
acetyl pyrazine.

Pyridines and pyrroles were another two aza-heterocyclic chemicals. They also came from the nucleophilic addition reaction of primary amine and carbonyl with the intramolecular reaction, not the intermolecular reaction. As illustrated in path 5 in Fig. 6, during the fast pyrolysis, the carbonyl group at $\mathrm{C}_{5}$ formed through the free radical transferring. Then, the amino group attacked this carbonyl group, producing a nitrogen-containing five-membered cyclic compound. This compound could be further converted to the pyrroles with the removal of substituents. Moreover, when the hydroxyl group at $\mathrm{C}_{6}$ was oxidized to an aldehyde group, the condition to form a nitrogen-containing six-membered cyclic compound through the intramolecular nucleophilic addition reaction had, as marked in pink in Fig. 6. Subsequently, this nitrogen-containing six-membered ring evolved into the pyridine ring, as shown in path 6 . The intramolecular nucleophilic addition reaction needed to overcome the steric hindrance, which restricted the formation of these five- and six-membered cyclic compounds. Thus, their selectivity was somewhat lower than that of pyrazines. 

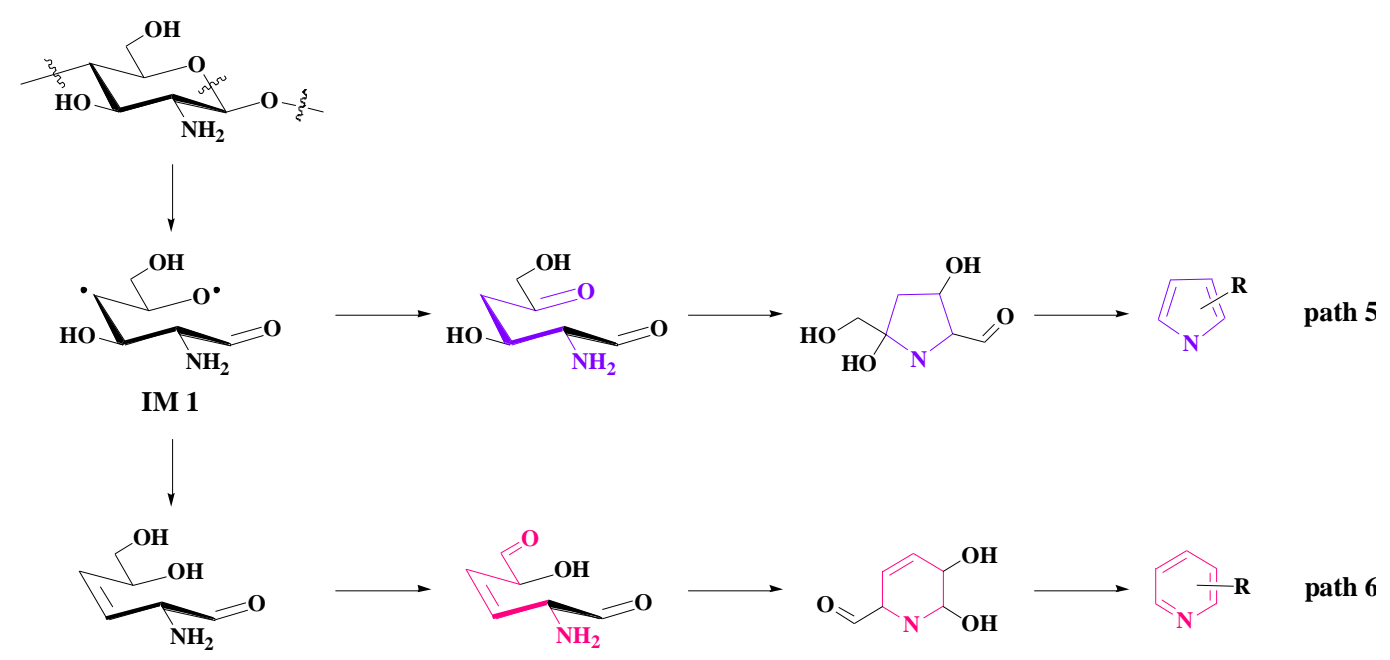

IM 4

Fig. 6 Proposed formation processes of pyridine compounds and pyrrole compounds from the fast pyrolysis of chitosan

\subsection{Acetamido chemicals from the fast pyrolysis of chitin}

Pyrolysis products from chitin under 350,450 , and $600{ }^{\circ} \mathrm{C}$ were listed in Table S2.

When the pyrolysis temperature was set at $350{ }^{\circ} \mathrm{C}$, only acetic acid, acetamide, and acetamido acetaldehyde were released, thus their selectivity was relatively high. With the temperature rose up, species of the pyrolysis products boomed. However, apart from the common products (acetic acid, acetamide, and certain small-molecule compounds), products from chitin were quite different with those from chitosan. As revealed in section 3.3, typical products from chitosan were aza-heterocyclic chemicals, including pyrazines, pyridines, and pyrroles. However, typical products from chitin were acetamido chemicals, e.g., N-ethenyl-N-methyl acetamide, acetamido acetaldehyde, 3-acetamidofuran, and so on. Herein, acetamido acetaldehyde was the most dominated product, whose selectivity 
was up to $27.27 \%$ at $450{ }^{\circ} \mathrm{C}$. This difference was caused by the different functional groups, i.e., the amino group in chitosan and the acetamido group in chitin, which proved that the free amino group (primary amine) was prone to produce aza-heterocyclic chemicals, whereas, the acetylated amino group would be maintained during pyrolysis. Furthermore, the detailed decomposition mechanisms of chitin pyrolysis were as follows.

Briefly, the formation of acetamido acetaldehyde profited from the cleavage of the glucosidic bond, the $\mathrm{C}_{1}-\mathrm{O}$ bond, and the $\mathrm{C}_{2}-\mathrm{C}_{3}$ bond during the pyrolysis of chitin, as marked in path 7 in Fig. 7. Previously, Franich, Goodin, \& Wilkins (1984) had proposed the detailed processes of acetamido acetaldehyde formation through the retro Diels-Alder reaction (path 8 in Fig. 7), which was also introduced into the explanation of cellulose pyrolysis (Vinu \& Broadbelt, 2012; Zhang, Geng, \& Yu, 2015). Furthermore, the retro Diels-Alder reaction could unveil the production of 3-acetamidofuran as well. As path 9 illustrated, during pyrolysis, the 1,4-oxygen-bridged bond would form with the glucosidic bond breaking and reconstructing, which resulted in the formation of the oxygen-containing five-membered cyclic structure (the purple ring). Soon afterwards, the hydroxyl group at $\mathrm{C}_{3}$ removed, leading to the generation of the $\mathrm{C}_{2}=\mathrm{C}_{3}$ bond, meeting the condition of the retro Diels-Alder reaction, forming hydroxyl acetaldehyde and 3-acetamidofuran. Moreover, the small amount of pyridines and pyrroles from chitin pyrolysis evolved through the intramolecular nucleophilic addition reaction as well along path 10 in Fig. 7. The difference was that the amino group in chitin was acetylated. The existence of the acetyl group limited the nucleophilic ability of $\mathrm{N}$ (both the steric 
hindrance and the negative induction effect) (Vollhardt, Schore, \& Freeman, 2003). Thus, the selectivity of aza-heterocyclic chemicals from chitin was much lower than that from chitosan.
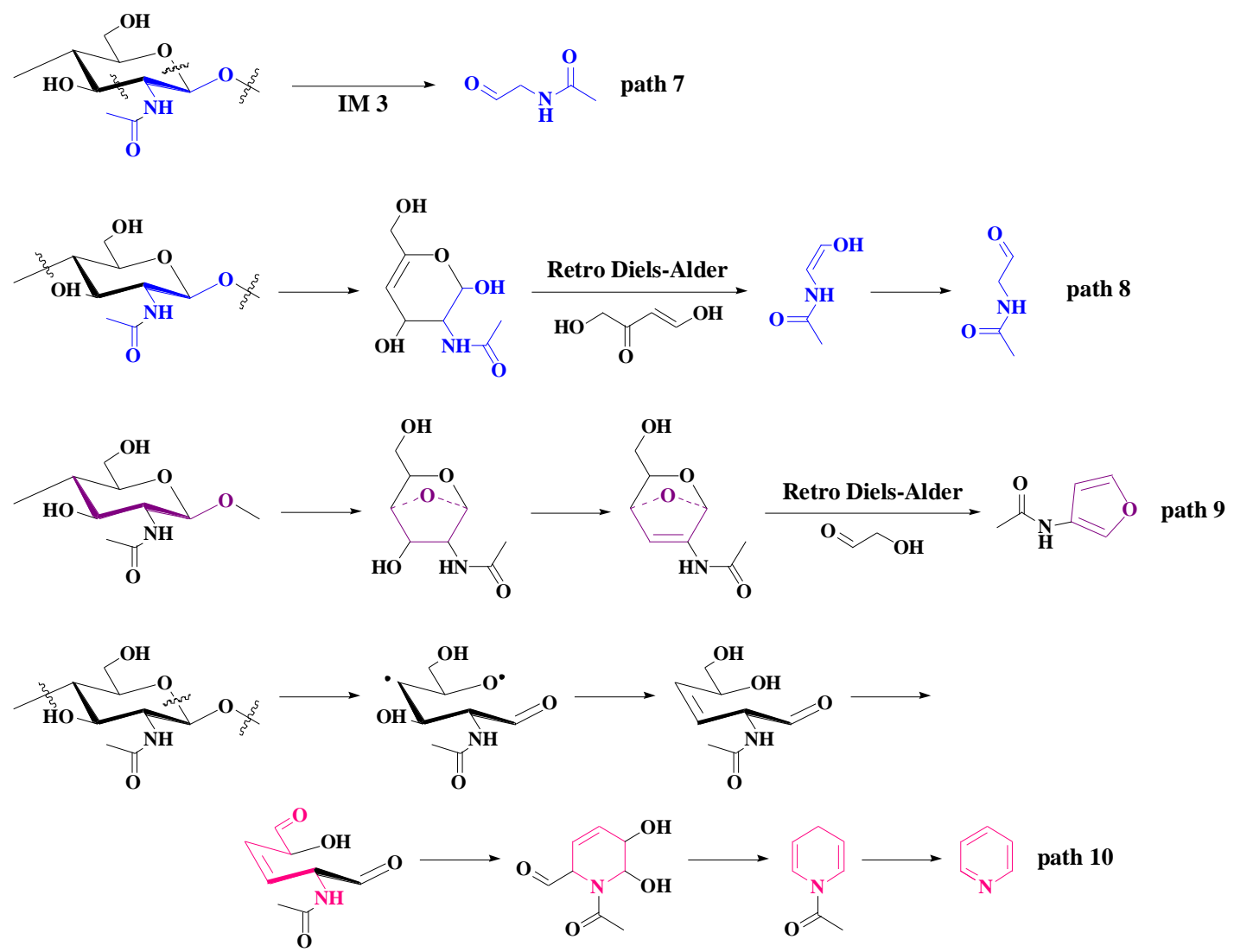

Fig. 7 Proposed formation processes of acetamido acetaldehyde, 3-acetamidofuran, and $\mathrm{N}$-acetyl-4(H)-pyridine from the fast pyrolysis of chitin

\section{Conclusions}

Chitosan had the potential to produce aza-heterocyclic chemicals, whereas chitin to acetamido chemicals. Pyridines, pyrazines, and pyrroles evolution from chitosan pyrolysis, whose total selectivity was $50.50 \%$ at $600{ }^{\circ} \mathrm{C}$, profited from the nucleophilic 
addition reaction of primary amine and carbonyl. Herein, selectivity of pyrazine compounds was up to $22.99 \%$. Moreover, acetamido chemicals from chitin pyrolysis were released through the ring-opening degradation, especially acetamido acetaldehyde with the highest selectivity of $27.27 \%$ at $450{ }^{\circ} \mathrm{C}$. All these differences were caused by the different content of acetamido group, which also led to the better thermal stability and higher activation energy of chitin, as well as its endothermic property during active pyrolysis.

\section{Acknowledgements}

The authors greatly acknowledge the funding support from the projects supported by the National Basic Research Program of China (973 Program, Grant nos. 2012CB215306 and 2013CB228101), the National Science Foundation for Distinguished Young Scientists of China (Grant no. 51525601), and the International (Regional) Cooperation and Exchange Program of the National Natural Science Foundation of China (Grant no. $51561145010)$.

\section{References}

Ball, R., Mcintosh, A. C., \& Brindley, J. (2004). Feedback processes in cellulose thermal decomposition: implications for fire-retarding strategies and treatments. Combustion Theory and Modelling, 8(2), 281-291.

Baran, T., Açıksöz, E., \& Menteş, A. (2016). Highly efficient, quick and green synthesis 
of biarlys with chitosan supported catalyst using microwave irradiation in the absence of solvent. Carbohydrate Polymers, 142, 189-198.

Baran, T., Inanan, T., Menteş, A. (2016). Synthesis, characterization, and catalytic activity in Suzuki coupling and catalase-like reactions of new chitosan supported Pd catalyst. Carbohydrate Polymers, 145, 20-29.

Baran, T., \& Menteş, A. (2015). Cu(II) and Pd(II) complexes of water soluble O-carboxymethyl chitosan Schiff bases: Synthesis, characterization. International Journal of Biological Macromolecules, 79, 542-554

Baran, T., Menteş, A., \& Arslan, H. (2015). Synthesis and characterization of water soluble O-carboxymethyl chitosan Schiff bases and $\mathrm{Cu}(\mathrm{II})$ complexes. International Journal of Biological Macromolecules, 72, 94-103.

Bierstedt, A., Stankiewicz, B. A., Briggs, D. E. G., \& Evershed, R. P. (1998). Quantitative and qualitative analysis of chitin in fossil arthropods using a combination of colorimetric assay and pyrolysis-gas chromatography-mass spectrometry. Analyst, 123(1), 139-145.

Bridgwater, A. V., Meier, D., \& Radlein, D. (1999). An overview of fast pyrolysis of biomass. Organic Geochemistry, 30(12), 1479-1493.

Chen, J., \& Ho, C. T. (1998). Volatile compounds formed from thermal degradation of glucosamine in a dry system. Journal of Agricultural Food Chemistry, 46(5), 1971-1974.

Chen, X., Chew, S. L., Kerton, F. M., \& Yan, N. (2014). Direct conversion of chitin into 
a N-containing furan derivative. Green Chemistry, 16(4), 2204-2212.

Chen, X., Gao, Y., Wang, L., Chen, H., \& Yan, N. (2015). Effect of treatment methods on chitin structure and its transformation into nitrogen-containing chemicals. ChemPlusChem, 80(10), 1565-1572.

Dong, Q., \& Xiong, Y. (2014). Kinetics study on conventional and microwave pyrolysis of moso bamboo. Bioresource Technology, 171, 127-131.

Dumanl1, A. G., \& Windle, A. H. (2012). Carbon fibres from cellulosic precursors: a review. Journal of Material Science, 47(10), 4236-4250.

Franich, R. A., Goodin, S. J., \& Wilkins, A. L. (1984). Acetamidofurans, acetamidopyrones, and acetamidoacetaldehyde from pyrolysis of chitin and N-acetylglucosamine. Journal of Analytical and Applied Pyrolysis, 7(1-2), 91-100.

Furuhashi, T., Beran, A., Blazso, M., Czegeny, Z., Schwarzinger, C., \& Steiner, G. (2009). Pyrolysis GC/MS and IR spectroscopy in chitin analysis of molluscan shells. Bioscience Biotechnology and Biochemistry, 73(1), 93-103.

Hu, J., Shen, D., Xiao, R., Wu, S., \& Zhang, H. (2013). Free-radical analysis on thermochemical transformation of lignin to phenolic compounds. Energy \& Fuels, 27(1), 285-293.

Kaczmarek, H., \& Zawadzki, J. (2010). Chitosan pyrolysis and adsorption properties of chitosan and its carbonizate. Carbohydrate Research, 345(7), 941-947.

Kasaai, M. R. (2009). Various methods for determination of the degree of N-acetylation of chitin and chitosan: a review. Journal of Agricultural and Food Chemistry, 57(7), 
1667-1676.

Kumar, M. N. V. R. (2010). A review of chitin and chitosan applications. Reactive \& Functional Polymers, 46(1), 1-27.

Kumar, M. N. V. R., Muzzarelli, R. A. A., Muzzarelli, C., Sashiwa, H., \& Domb, A. J. (2004). Chitosan chemistry and pharmaceutical perspectives. Chemical Reviews, 104(12), 6017-6084.

Lal, G. S., \& Hayes, E. R. (1984). Determination of the amine content of chitosan by pyrolysis-gas chromatography. Journal of Analytical and Applied Pyrolysis, 6(2), 183-193.

Li, X., Liu, B., Wang, X., Han, Y., Su, H., Zeng, X., \& Sun, R. (2012). Synthesis, characterization and antioxidant activity of quaternized carboxymethyl chitosan oligosaccharides, Journal of Macromolecular Science, Part A, 49(10), 861-868.

Liang, J., Lin, Y., Wu, S., Liu, C., Lei, M., \& Zeng, C. (2015). Enhancing the quality of bio-oil and selectivity of phenols compounds from pyrolysis of anaerobic digested rice straw. Bioresource Technology, 181, 220-223.

Mettler, M. S., Mushrif, S. H., Paulsen, A. D., Javadekar, A. D., Vlachos, D. G., \& Dauenhauer, P. J. (2012). Revealing pyrolysis chemistry for biofuels production: Conversion of cellulose to furans and small oxygenates. Energy \& Environmental Science, 5(1), 5414-5424.

Pastorova, I., Botto, R. E., Arisz, P. W., \& Boon, J. J. (1994). Cellulose char structure: a combined analytical Py-GC-MS, FTIR, and NMR study. Carbohydrate Research, 
262(1), 27-47.

Qiao, Y., Chen, S., Liu, Y., Sun, H., Jia, S., Shi, J., Pedersen, C. M., Wang, Y., \& Hou, X. (2015). Pyrolysis of chitin biomass: TG-MS analysis and solid char residue characterization. Carbohydrate Polymers, 133, 163-170.

Sato, H., Mizutani, S., Tsuge, S., Ohtani, H., Aoi, K., Takasu, A., Okada, M., Kobayashi, S., Kiyosada, T., \& Shoda, S. (1998). Determination of the degree of acetylation of chitin/chitosan by pyrolysis-gas chromatography in the presence of oxalic acid. Analytical Chemistry, 70(1), 7-12.

Shen, D.K., \& Gu, S. (2009). The mechanism for thermal decomposition of cellulose and its main products. Bioresource Technology, 100(24), 6496-6504.

Singh, S. K., \& Ekhe, J. D. (2014). Solvent effect on HZSM-5 catalyzed solvolytic depolymerization of industrial waste lignin to phenols: superiority of the water-methanol system over methanol. RSC Advances 4(95), 53220-53228.

Stolarek, P., \& Ledakowicz, S. (2005). Pyrolysis kinetics of chitin by non-isothermal thermogravimetry. Thermochimica Acta, 433(1-2), 200-208.

Tang, W., Wang, C., \& Chen, D. (2005). Kinetic studies on the pyrolysis of chitin and chitosan. Polymer Degradation and Stability, 87(3), 389-394.

Vinu, R., \& Broadbelt, L. J. (2012). A mechanistic model of fast pyrolysis of glucose-based carbohydrates to predict bio-oil composition. Energy \& Environmental Science, 5(12), 9808-9826.

Vollhardt, K. P. C., Schore, N. E., \& Freeman, W. H. (2003). Organic chemistry: 
structure and function. New York: WH Freeman and company.

Wang, S., Ru, B., Lin, H., \& Luo, Z. (2013). Degradation mechanism of monosaccharides and xylan under pyrolytic conditions with theoretic modeling on the energy profiles. Bioresource Technology, 143, 378-383.

Wang, W., Ren, J., Li, H., Deng, A., \& Sun, R. (2015). Direct transformation of xylan-type hemicelluloses to furfural via $\mathrm{SnCl}_{4}$ catalysts in aqueous and biphasic systems. Bioresource Technology, 183, 188-194.

Yang, H., Yan, R., Chen, H., Lee, D. H., \& Zheng, C. (2007). Characteristics of hemicellulose, cellulose and lignin pyrolysis. Fuel, 86(12-13), 1781-1788.

Zeng, L., Hu, X., Gu, N., Fu, B., \& Qin, C. (2015). Investigation of volatile chemicals and their distributions from pyrolysis of chitin by FT-IR and GC-MS. Journal of Analytical and Applied Pyrolysis, 112, 357-362.

Zeng, L., Qin, C., Wang, L., \& Li, W. (2011). Volatile compounds formed from the pyrolysis of chitosan. Carbohydrate Polymers, 83(4), 1553-1557.

Zhang, M., Geng, Z., \& Yu, Y. (2015). Density functional theory (DFT) study on the pyrolysis of cellulose: the pyran ring breaking mechanism. Computational and Theoretical Chemistry, 1067, 13-23.

Zhao, L., Baccile, N., Gross, S., Zhang, Y., Wei, W., Sun, Y., Antonietti, M., \& Titirici, M. (2010). Sustainable nitrogen-doped carbonaceous materials from biomass derivatives. Carbon, 48(13), 3778-3787. 